\title{
PhET NA PERSPECTIVA DO ENSINO DE CIÊNCIAS - UMA ANÁLISE DO CONHECIMENTO E USO DO SOFTWARE POR MESTRANDOS DO MPECIM/2020
}

1 Abigail Santana

1 Eliane Merklein

1 Géssica Sampaio

1 Discentes do Curso de Mestrado Profissional em Ensino de Ciências e Matemática - MPECIM, Universidade Federal do Acre - UFAC, Rio Branco, Acre, Brasil. abigailsantana70@gmail.com

elianemerklein@gmail.com

gsampaio516@gmail.com

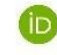

(iD)

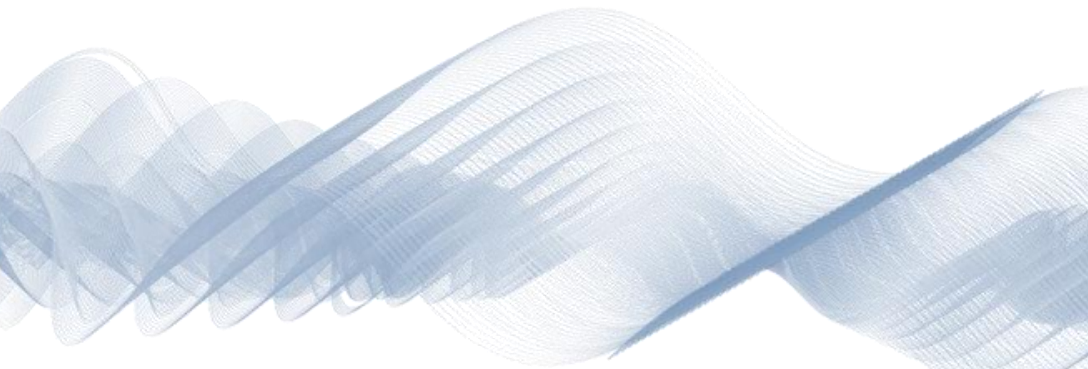

\section{RESUMO}

Atualmente, muito se discute sobre o uso das tecnologias para fins didáticos pedagógicos. Na literatura encontram-se diversas pesquisas que buscam oferecer alternativas para contribuir significativamente na qualidade do ensino nessa área. Os softwares de simulação virtual, são uma dessas alternativas, pois, proporcionam uma melhor compreensão dos conteúdos abstratos no Ensino de Ciências, promovendo os aspectos de uma aula experimental ao exercer um papel facilitador na construção do conhecimento. Nesse sentido, este trabalho tem como principal objetivo investigar as percepções acerca do conhecimento e uso do simulador PhET com os mestrandos da turma de 2020 do Mestrado Profissional Ensino de Ciências e Matemática (MPECIM) após a apresentação tutorial deste recurso realizado pelas autoras. Para isso foi utilizada uma abordagem qualitativa com aspectos descritivos, dividido em quatro etapas: a) Apresentação e discussão de um texto base; b) Apresentação dialogada de um guia didático com intuito de instruir os participantes na utilização e aplicabilidade do PhET; c) Avaliação do conhecimento e impressões obtidas pelos participantes em torno do uso do simulador. Os resultados se mostraram satisfatórios evidenciando que o PhET, pode ser utilizado como recurso inovador, didático despertando interesse e curiosidade, incentivando, assim o estudante a uma aprendizagem mais ativa e significativa.

PALAVRAS-CHAVE: Tecnologia. Ensino de Ciências. Estratégia de Ensino. Simulador Virtual. 


\title{
PhET FROM THE PERSPECTIVE OF SCIENCE TEACHING - AN ANALYSIS OF THE KNOWLEDGE AND USE OF THE SOFTWARE BY MASTER'S STUDENTS AT MPECIM/2020
}

\begin{abstract}
Currently, much is discussed about the use of technologies for pedagogical didactic purposes. There are several studies in the literature that seek to offer alternatives to significantly contribute to the quality of teaching in this area. Virtual simulation software is one of these alternatives, as they provide a better understanding of abstract contents in Science Teaching, promoting aspects of an experimental class by playing a facilitating role in the construction of knowledge. In this sense, this work has as main objective to investigate the perceptions about the knowledge and use of the PhET simulator with the master's students of the 2020 class of the Professional Master's Degree in Science and Mathematics Teaching (MPECIM) after the tutorial presentation of this resource carried out by the authors. For this, a qualitative approach with descriptive aspects was used, divided into four stages: a) Presentation and discussion of a basic text; b) Dialogue presentation of a didactic guide with the aim of instructing participants in the use and applicability of PhET; c) Assessment of the knowledge and impressions obtained by the participants regarding the use of the simulator. The results were satisfactory, showing that PhET can be used as an innovative, didactic resource, arousing interest and curiosity, thus encouraging the student to learn more actively and meaningfully.
\end{abstract}

KEYWORDS: Technology. Science teaching. Teaching Strategy. Virtual Simulator. 


\section{INTRODUÇÃO}

Não é de hoje que a sociedade vive uma cultura digital onde o processo de aproximação entre as pessoas, a construção e reconstrução do conhecimento e de opiniões são mediados, em grande parte, por meio das tecnologias digitais. Hoje, mais do que nunca, essa cultura foi fortalecida com a pandemia causada pela COVID-19. Logo, a inserção das Tecnologias Digitais de Informação e Comunicação (TDICs) no meio educacional tornam-se relevantes no processo de ensino aprendizagem, proporcionando ao estudante a oportunidade de aprender através da ferramenta que está consigo constantemente.

O Ensino de Ciências deve favorecer a familiaridade entre o objeto de estudo e o estudante, para oportunizar a interpretação científica dos fenômenos no cotidiano. A cada época há um conjunto de tecnologias que contribuem para a construção do conhecimento, fazer uso delas dentro do sistema educacional impulsiona a aprendizagem, além de promover mudanças comportamentais e atitudinais relacionadas à motivação no estudo (1).

Diante ao cenário atual, principalmente na educação, seja ela em todas as suas modalidades, desde a educação básica ao ensino superior, o que se pode observar é, o quão importante tem sido o uso e aplicação das tecnologias digitais para o processo de ensino e aprendizagem, pois graças à tais recursos o processo de construção do conhecimento não parou. Estudantes e professores encontram-se tão longe "fisicamente", mas tão pertos "virtualmente".

Por conta de suas potencialidades no processo de ensino e aprendizagem, as TDICs vêm ganhando espaço significativo dentro do Ensino de Ciências. Pois, partindo de uma estratégia de ensino, contribui para que o estudante interaja com a ciência e integre ela em seu saber, tornando-o hábil para exercer sua cidadania com responsabilidade e consciência.

"A procura constante por novos recursos metodológicos e tecnológicos vem sendo um fator importante a ser compreendido pelos educadores durante 0 isolamento social e a aplicação do ensino síncrono remoto" (RODRIGUES, et al., 2020 , p. 1 (2). Conforme relatado, tal procura têm acontecido em todas as esferas de 
ensino, no curso de mestrado não é diferente, onde docentes e mestrandos buscaram por adaptações para que o curso tivesse continuidade.

Assim, a presente pesquisa teve sua abordagem voltada para a Disciplina "Tecnologias e Materiais Didáticos para o Ensino de Ciências" ofertada no Curso de Mestrado Profissional em Ensino de Ciências e Matemática - MPECIM da Universidade Federal do Acre - UFAC, a qual no decorrer do processo tratou de conhecimentos e explanações de diversos recursos tecnológicos educacionais, sendo um deles, o software PhET (simulador virtual), objeto de maior ênfase nesta pesquisa.

Esses softwares de simulação podem ser utilizados paralelamente com as aulas expositivas em sala de aula, porque não expõem os alunos a riscos de acidentes, não há gastos de reagentes e não gera resíduos de substâncias Químicas nocivas à natureza (PINHEIRO; ARAÚJO; PESSOA JÚNIOR, 2015, p. 3. (3).

O Ensino de Ciências precisa associar teoria e prática, mas como promover prática diante de isolamento social? Pensando nisso, o simulador virtual PhET pode ser um dos recursos para auxiliar a prática das aulas de ciências, pois trata-se de um software simples e prático de ser utilizado, tanto por professores quanto por estudantes, além disso tem um diferencial, pode ser utilizado de forma online como também offline. É possível trabalhar com simulações de experimentos no formato online, como também, é possível fazer o download da atividade de simulação.

Para que seja posto em prática o uso de softwares de simulação virtual no processo de ensino é necessário que os educadores conheçam tal ferramenta e suas aplicabilidades. Diante disso elaborou-se a seguinte problemática: qual o parecer dos educadores no Ensino de Ciências ao conhecerem as aplicabilidades, vantagens e limitações do PhET - simulador virtual interativo?

Com base na problemática exposta, esta pesquisa objetivou investigar as percepções acerca do simulador PhET com os mestrandos da turma de 2020 do MPECIM após a apresentação tutorial deste recurso realizado pelas autoras. Os mestrandos participantes da pesquisa são todos professores da Educação Básica.

Esta pesquisa apresenta quatro seções: a primeira seção aborda brevemente as TDICs no Ensino de Ciências e a problemática do tema; na segunda seção é abordado o método de pesquisa e a descrição do contexto em que se ocorreu; na 
terceira seção o resultado é apresentado e analisado qualitativamente; e, a quarta seção é destinada às considerações finais.

\section{MATERIAL E MÉTODOS}

A metodologia abordada foi de uma pesquisa qualitativa, oriunda de um estudo descritivo realizado por um grupo de mestrandos (as autoras) durante a disciplina "Tecnologias e Materiais para o Ensino de Ciências", ministrada pela professora Dra Adriana Ramos dos Santos aos mestrandos da turma de 2020, no período de 10 de dezembro de 2020 a 28 de janeiro de 2021, do Mestrado Profissional "Ensino de Ciências e Matemática" (MPECIM/UFAC), sendo os participantes do estudo, os próprios mestrandos da turma.

Esse trabalho trata-se de um estudo descritivo exploratório, com abordagem metodológica qualitativa. Na coleta de dados utilizou-se um questionário semiestruturado no Google Forms para explorar a postura dos mestrandos em relação ao conhecimento e uso do recurso (simulador PhET).

A metodologia utilizada no presente estudo é descritiva em razão de tentar descrever as percepções dos participantes em relação ao software PhET (simulador virtual). E, para alcançar o objetivo proposto, o presente estudo foi realizado em quatro etapas:

1. Etapa: Em uma das aulas da disciplina, as autoras, por meio de slides, realizou uma apresentação e discussão do texto base "A Abordagem Didática da Simulação Virtual no Ensino da Química: Um olhar para os novos paradigmas da Educação"(4), previamente disponibilizado pela professora da disciplina (Figura 1). 
Multidisciplinary Sciences Reports

Figura 1 - Lâmina de apresentação texto base. Fonte: as autoras.

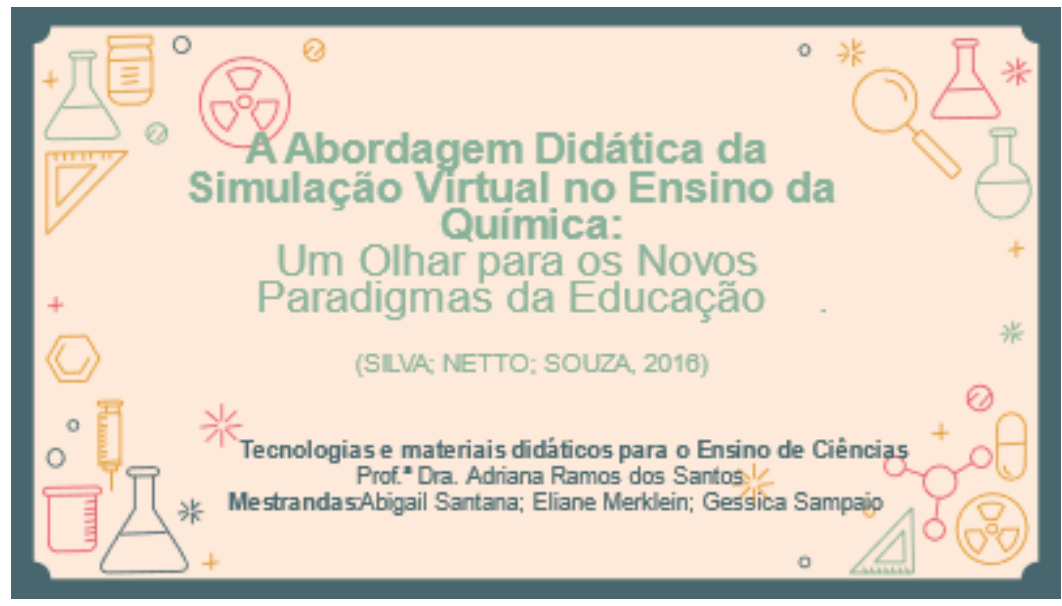

2a Etapa: Consistiu da elaboração de um guia didático, detalhando o passo a passo de como utilizar o simulador virtual PhET. Bem como a elaboração de uma atividade preparada utilizando o recurso tecnológico "WebQuest" para ser desenvolvida pelos mestrandos participantes para o conhecimento e uso do PhET, veja as Figuras 2 e 3.

Mult. Sci. Rep. 2021; v. 1 n. 2 / ISSN: 2764-3888

DOI: https://doi.org/10.54038/ms.v1i2.13

Submetido: 15 Setembro, 2021 - Aceito: 15 Outubro, 2021 
Multidisciplinary Sciences Reports

Figura 2 - Guia Didático - PhET. Fonte: as autoras.

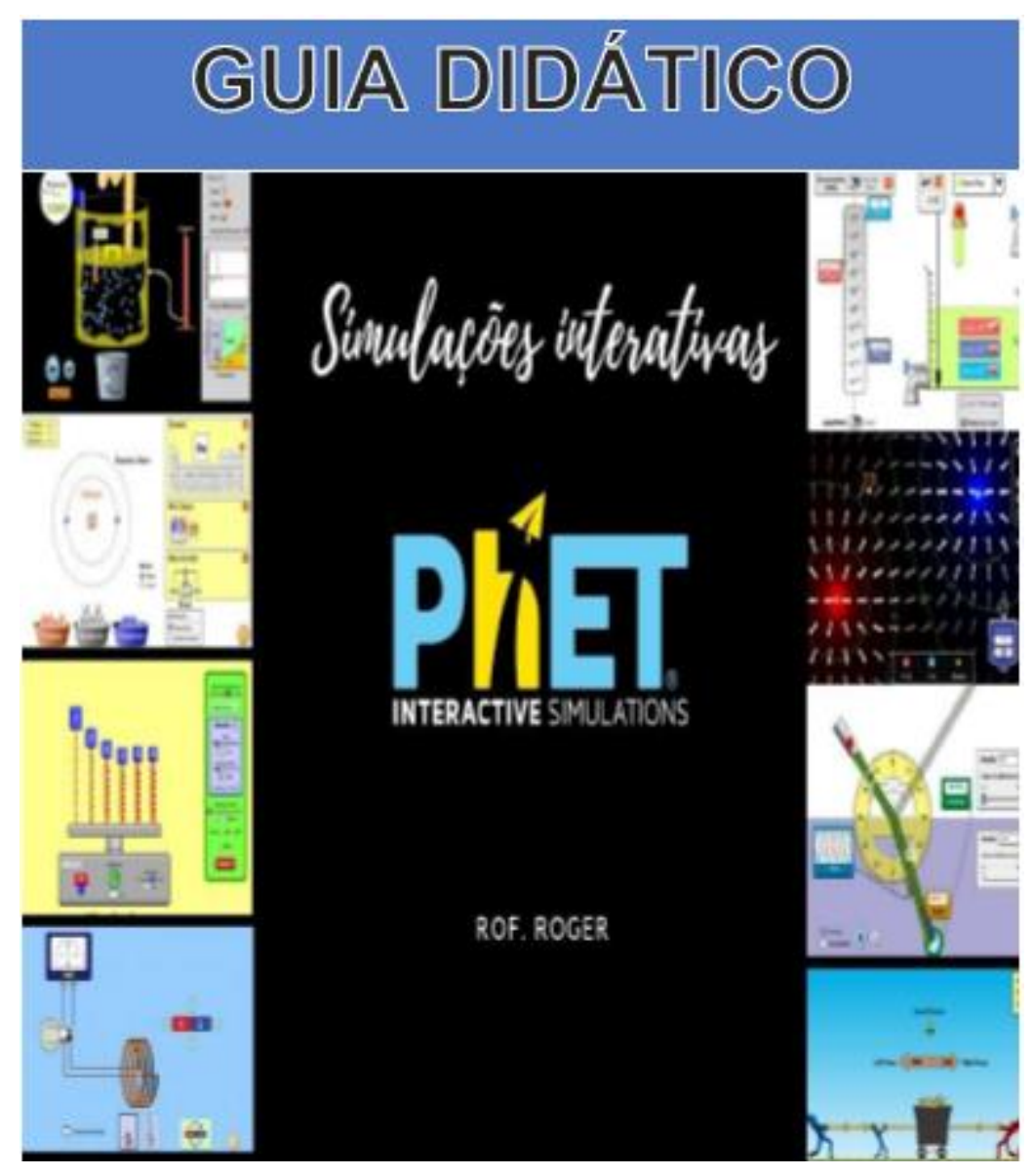

Figura 3 - Página da atividade WebQuest. Fonte: as autoras.

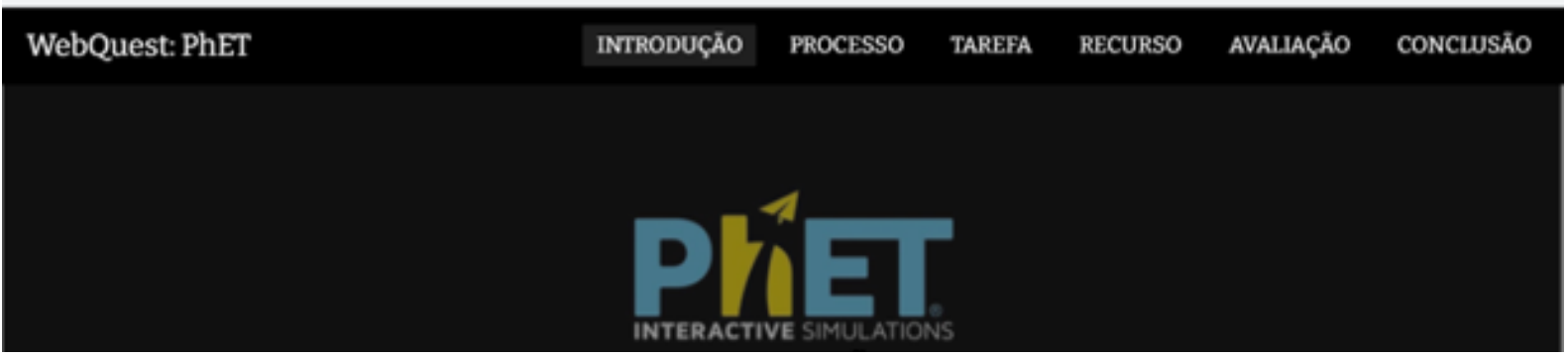

3ª Etapa: Em aula seguinte da disciplina e de forma remota, utilizando o google Meet, foi realizada uma apresentação expositiva e dialogada do guia didático, ao qual aborda de modo detalhado as principais funcionalidades e aplicabilidades do PhET no Ensino de Ciências. A partir desta abordagem, foi disponibilizado aos mestrandos um link disponível na referência 
(https://sites.google.com/view/webquestphet/introdu\%C3\%A7\%C3\%A30) de uma atividade a ser realizada para vivenciar na prática o uso do simulador virtual PhET, esta atividade foi realizada por meio do recurso WebQuest. Os mestrandos participantes receberam o link para que pudessem acessar a atividade e seguir os comandos. Nesta atividade, havia uma tarefa a ser realizada por todos e para isso, deveriam acessar um link que direcionava para a página do PhET onde deveriam seguir todos os passos solicitados pela tarefa designada na WebQuest. Tratava-se de uma atividade que iria proporcionar uma experiência com uma simulação virtual dentro da área de Química (balanceamento de equações), conforme ilustrado nas Figuras 4 a 9 referentes as fases da WebQuest.

Figura 4 - Atividade WebQuest - Introdução. Fonte: as autoras.

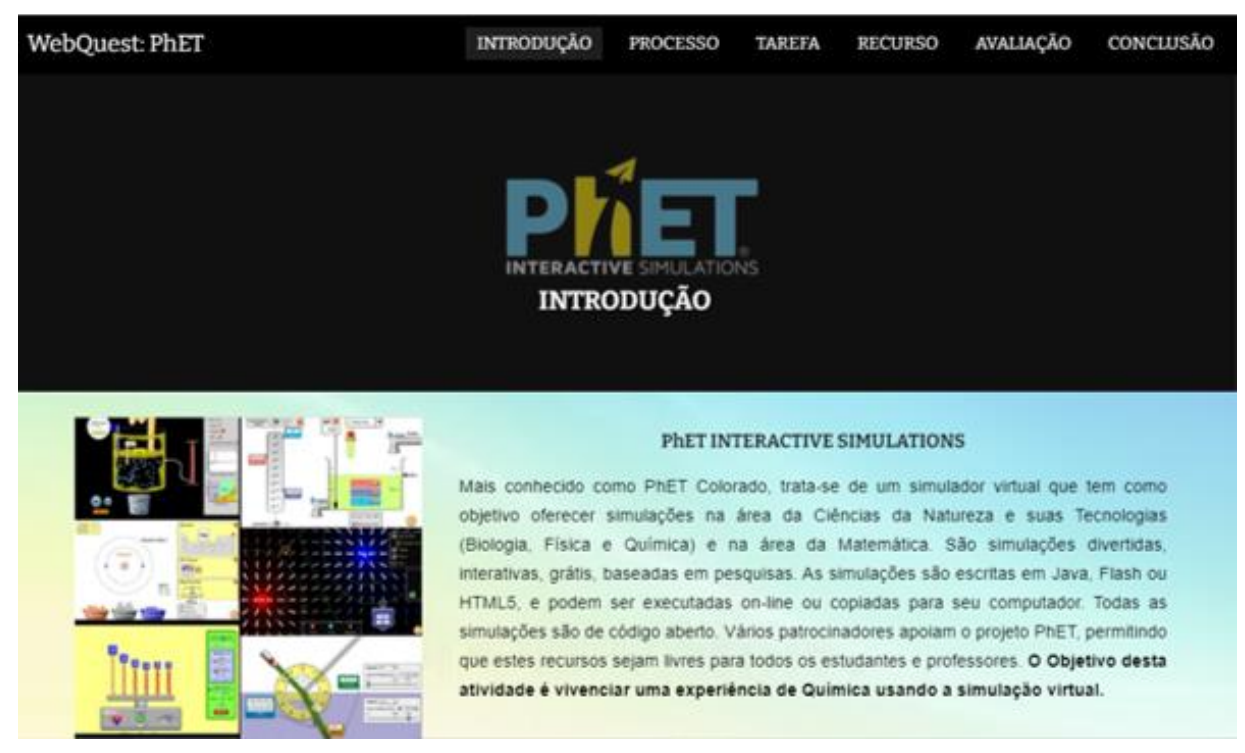

Mult. Sci. Rep. 2021; v. 1 n. 2 / ISSN: 2764-3888

DOI: https://doi.org/10.54038/ms.v1i2.13

Submetido: 15 Setembro, 2021 - Aceito: 15 Outubro, 2021 
Figura 5 - Atividade WebQuest - Processo. Fonte: as autoras.

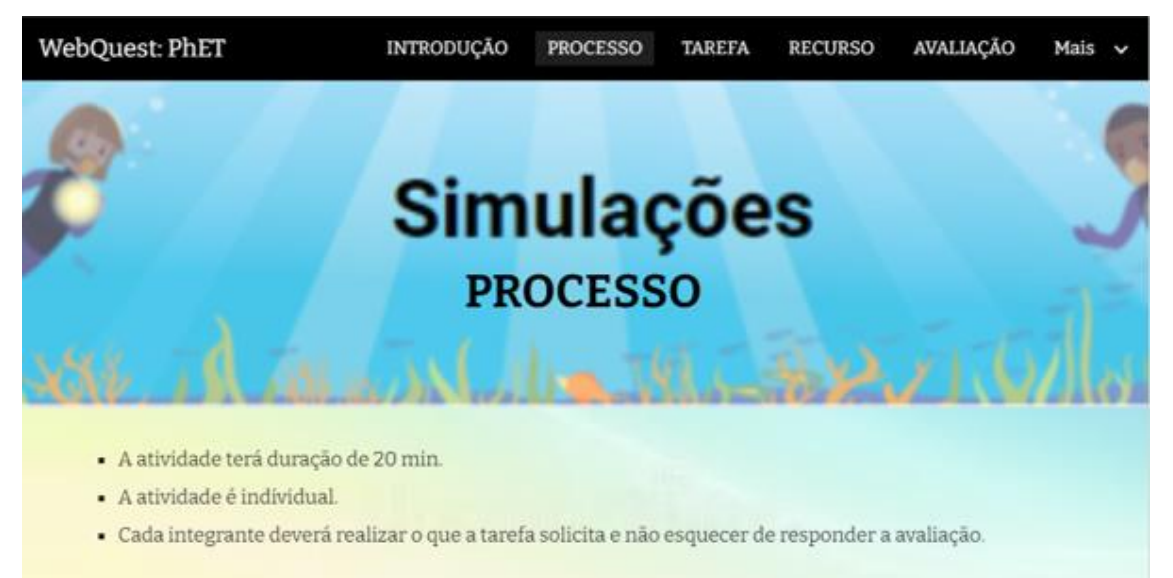

Figura 6 - Atividade WebQuest- Tarefa. Fonte: as autoras.

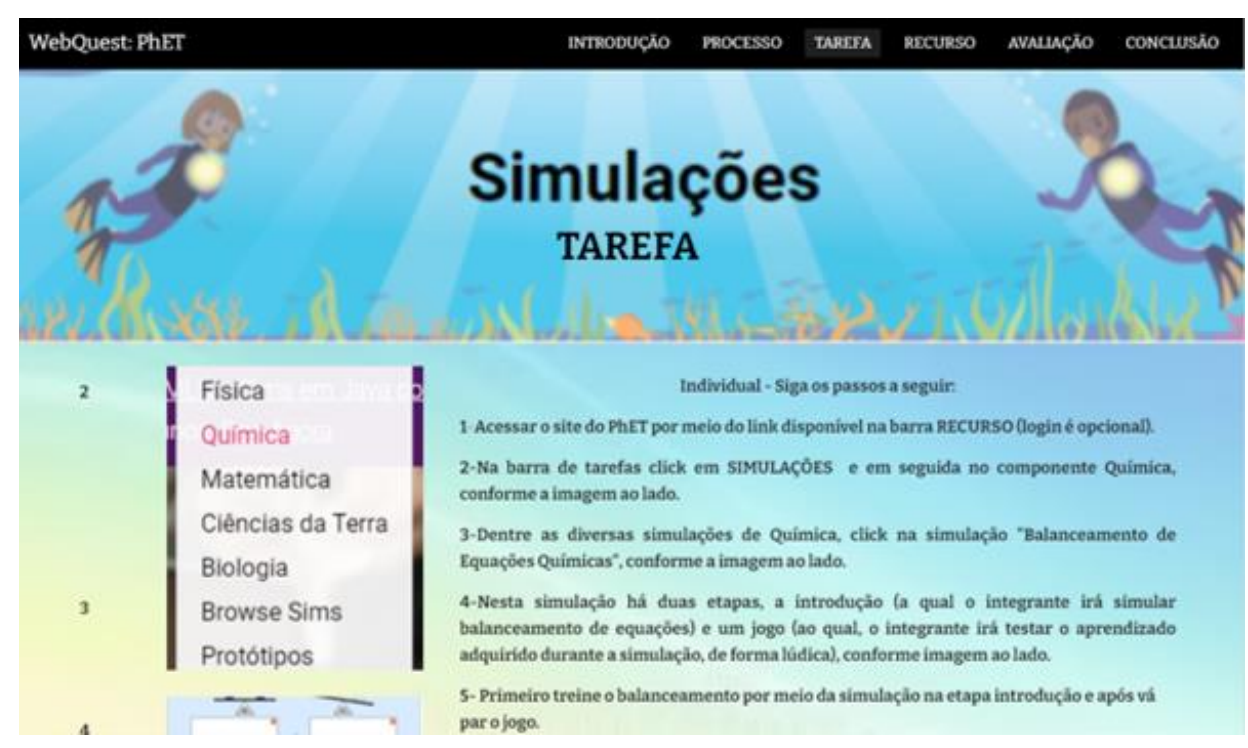

Figura 7 - Atividade WebQuest- - Recurso. Fonte: as autoras.

\section{Simulações} RECURSO

- PhET - httpsil/phetcoloradoedu/pt BR/

Mult. Sci. Rep. 2021; v. 1 n. 2 / ISSN: 2764-3888

DOI: https://doi.org/10.54038/ms.v1i2.13

Submetido: 15 Setembro, 2021 - Aceito: 15 Outubro, 2021 
Figura 8 - Atividade WebQuest - Avaliação. Fonte: as autoras.

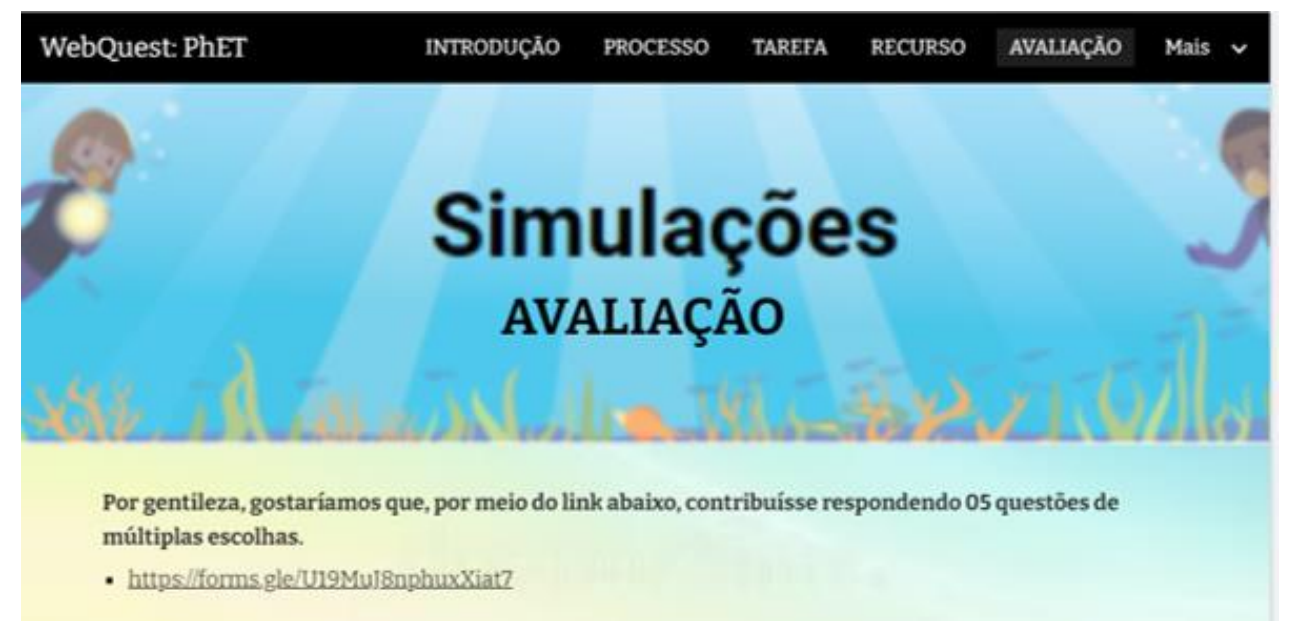

Figura 9 - Atividade WebQuest - Conclusão. Fonte: as autoras.

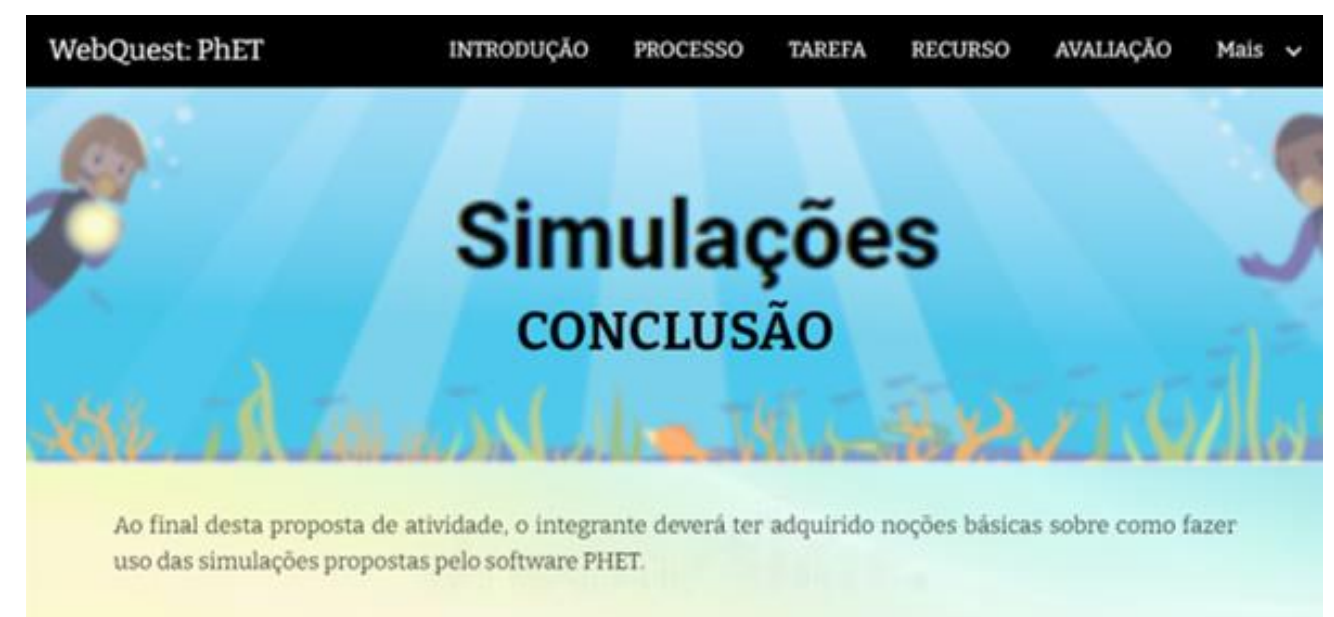

4a Etapa: Ao final da experiência, os mestrandos precisaram responder a avaliação (Figura 8) sobre a vivência/experimentação com o simulador virtual. A avaliação foi preparada utilizando o formulário Google Forms, no qual o link estava disponibilizado na aba "Avaliação". O formulário continha 5 questões, as quais foram respondidas por 10 participantes. 
Figura 10 - Formulário Google Forms - Questões 1 a 5. Fonte: as autoras.

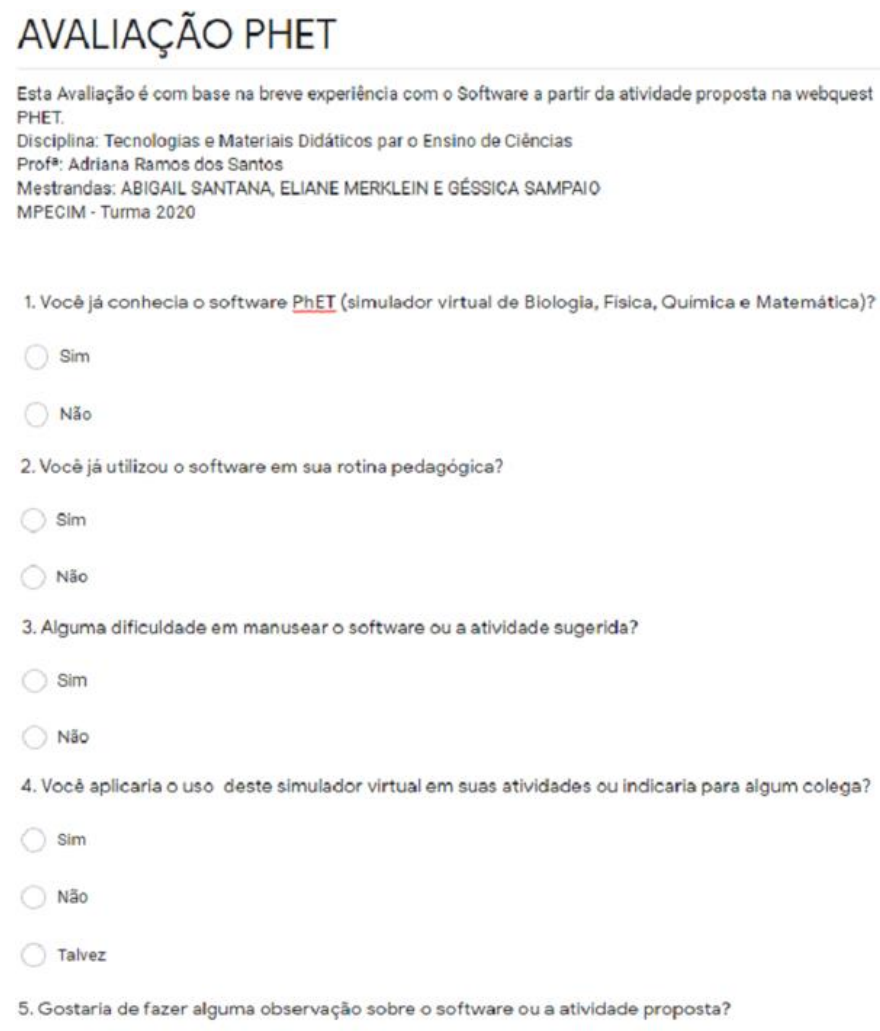

\section{RESULTADOS E DISCUSSÕES}

\section{Apresentação do Guia didático:}

Os resultados obtidos em relação a apresentação do guia didático como elemento introdutório, mostrou-se de grande valia no quesito instrução e orientação inicial para os mestrandos visando a utilização e aplicabilidade do PhET.

\section{Elaboração do jogo interativo:}

O PhET é um simulador virtual que tem como principal característica prender a atenção do aluno, proporcionando entusiasmo para jogar, competir e ganhar pontos. A utilização dessa ferramenta pôde possibilitar uma maior motivação e incentivo para a realização da atividade proposta, despertando interesse dos participantes, tornandoa mais atraente e colocando os mestrandos em posição de protagonistas no processo de construção do próprio conhecimento. 
De acordo com Silva, Netto e Souza (2016) (4), o ambiente gamificado tem despertado interesse dos docentes da área, trazendo diversos benefícios na aprendizagem do aluno, dentre eles a exigência de um nível de concentração maior nas atividades efetuadas e possibilitam a aprendizagem dos conceitos.

\section{Aplicação do questionário:}

O resultado da avaliação realizada com os mestrandos da turma MPECIM 2020, estão representados pelas figuras e descritos abaixo:

Figura 11 - Gráfico das respostas referentes à questão 1. Fonte: as autoras.

1. Você já conhecia o software PHET (simulador virtual de Biologia, Fisica, Quimica e Matemática)? 10 respostas

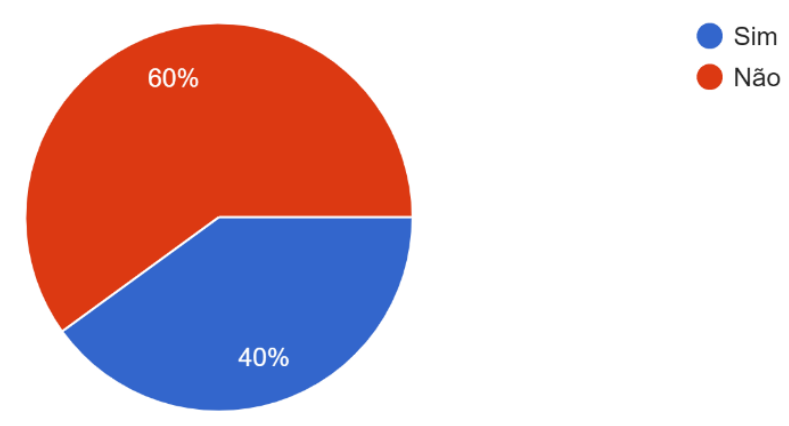

Figura 12 - Gráfico das respostas referentes à questão 2. Fonte: as autoras.

2. Você já utilizou o software em sua rotina pedagógica?

10 respostas

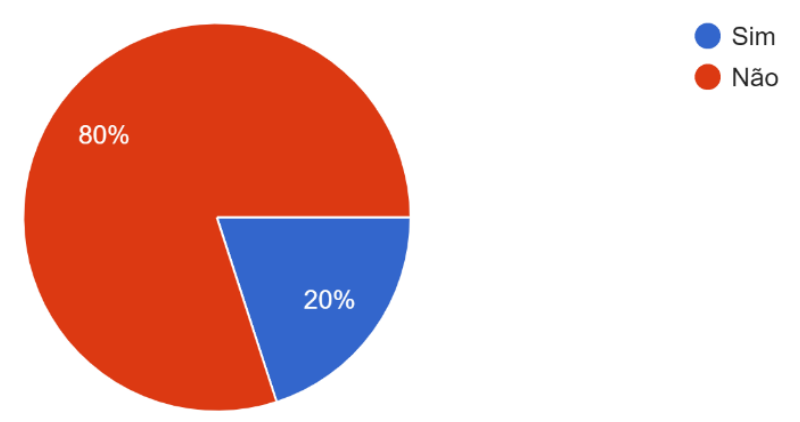

Mult. Sci. Rep. 2021; v. 1 n. 2 / ISSN: 2764-3888

DOI: https://doi.org/10.54038/ms.v1i2.13

Submetido: 15 Setembro, 2021 - Aceito: 15 Outubro, 2021 
Figura 13 - Gráfico das respostas referentes à questão 3. Fonte: as autoras.

3. Alguma dificuldade em manusear o software ou a atividade sugerida? 10 respostas

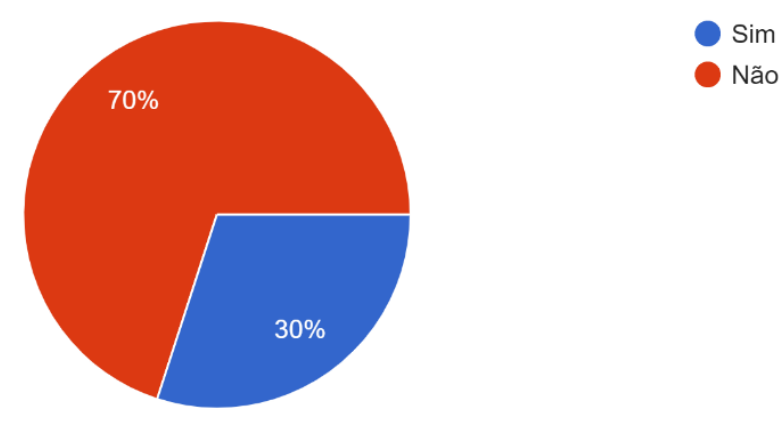

Figura 14 - Gráfico das respostas referentes à questão 4. Fonte: as autoras.

4. Você aplicaria o uso deste simulador virtual em suas atividades ou indicaria para algum colega? 10 respostas

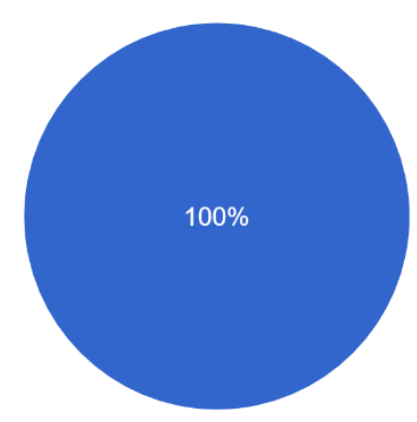

$$
\begin{aligned}
& \text { Sim } \\
& \text { Não } \\
& \text { Talvez }
\end{aligned}
$$

Mult. Sci. Rep. 2021; v. 1 n. 2 / ISSN: 2764-3888

DOI: https://doi.org/10.54038/ms.v1i2.13 
Figura 15 - Respostas referentes à questão 5. Fonte: as autoras.

5. Gostaria de fazer alguma observação sobre o software ou a atividade proposta?

7 respostas

É uma ferramenta muito útil

Sem observação a fazer, porém gostei muito da atividade de balanceamento.

Muito bom esse software.

Ótima atividade, parabéns pela proposta!!

Gostaria de saber porque ele não abriu...

O software é ótimo. Dinâmico.

Otimo software muito interativo e didático !!!

Diante dos resultados obtidos com a avaliação realizada pelos mestrandos participantes, é possível observar que 60\% (6/10) dos participantes responderam que não conheciam o software PhET (figura 11), 80 \% (8/10) responderam que nunca havia feito uso do simulador durante sua prática pedagógica (figura 12), 70 \% (7/10) responderam que acharam o software de fácil execução (figura 13) e 100\% (10/10) afirmaram que aplicariam o simulador virtual PhET em suas práticas pedagógicas, bem como indicariam para outros colegas.(figura 14).

Além disso, pôde-se constatar por meio das respostas da $5^{\underline{a}}$ questão que 0 software PhET foi bem avaliado com os comentários deixados pelos participantes, como: "Uma ferramenta muito útil" e outro comentário como: "Ótimo software muito interativo e didático". De todos os participantes apenas um teve dificuldades técnicas no acesso do software, talvez em razão de acesso.

Em pesquisas na internet, com os trabalhos como os realizados pelos autores Ramos et al (2020) (6), Carraro e Pereira (2014) (7) e Leal et al (2020) (8), foi possível constatar abordagens relacionadas ao uso e aplicação do simulador virtual, PhET nas aulas de Ciências (física, matemática, química) perpassando por séries da educação 
básica. Comparando a pesquisa destes autores com esta pesquisa, é possível perceber o quanto é evidenciado nos resultados a importância da utilização deste software como instrumento auxiliar nas aulas de ciências. E, apesar do público participante desta pesquisa (estudantes de mestrado) ser diferente do público participante nas pesquisas dos demais autores (estudantes da Educação Básica), é possível perceber que os objetivos são comuns, "avaliar o uso e aplicação do simulador PhET nas aulas de ciências", constatando em todos os resultados obtidos que o software pode ser um instrumento auxiliar nas aulas de ciências.

\section{CONCLUSÃO}

Diante do que foi exposto, é possível afirmar que a Disciplina de "Tecnologia e Materiais Didáticos para o Ensino de Ciências" possibilitou não apenas aos participantes desta pesquisa, como também as autoras deste trabalho conhecer e explorar recursos didáticos disponíveis por meio da tecnologia. Assim e apesar dos resultados evidenciarem pouco conhecimento e aplicação do simulador por parte dos participantes em sua prática pedagógica, conclui-se que a partir das experiências vivenciadas se mostraram satisfatórios para o uso e aplicação do PhET como recurso inovador, didático que desperta o interesse e a curiosidade, incentivando assim, o estudante a uma aprendizagem mais ativa e significativa.

Desta forma, é possível observar que trabalhos desta natureza são importantes, pois mesmo os participantes estarem cursando um mestrado, estes, em sua maioria, não conheciam ou tiveram acesso ao simulador, o que leva a concluir que ainda são poucas as apropriações por parte dos educadores quanto aos recursos tecnológicos disponíveis. O PhET é um dos recursos didáticos disponíveis, porém, nem todos o conhecem ou têm acesso e utilizam em suas aulas.

\section{REFERÊNCIAS}

1. Silva, Wender Antonio da; Kalhil JB. Digital Technologies in Science Teaching: Reflections and. 2018;77-91. Available from: http://erevista.unioeste.br/index.php/rebecem/article/view/19155 
2. Rodrigues $Y$, Coelho F, Médio E, Coelho AF, Santos MS. A UTILIZAÇÃO DE SIMULADORES VIRTUAIS NO ENSINO DA ROBÓTICA DURANTE A PANDEMIA A mesma oferece uma interface de hardware proporcionando. 2020;1-6.

3. Pinheiro AF, Araújo MD de, Pessoa Júnior ESF. Software De Simulação : Um Recurso Facilitador No Processo De Ensino E Aprendizagem De Química No. XII Congr Nac Educ [Internet]. 2015;2042-57. Available from: https://educere.bruc.com.br/arquivo/pdf2015/16888_7936.pdf

4. Silva G, Netto JF, Souza R. A Abordagem Didática da Simulação Virtual no Ensino da Química: Um Olhar para os Novos Paradigmas da Educação. An do XXII Work Informática na Esc (WIE 2016). 2016;1(CBIE):339.

5. WebQuest: PhET.

6. Ramos M, Cardoso K, Carvalho MCS. O Ensino De Ciências Com O Uso Da Ferramenta Digital Simulador Phet Por Meio Da Estratégia Investigativa Nos Anos Finais Do .... An do CIET EnPED 2020 ... [Internet]. 2020;1-12.

Available from:

https://cietenped.ufscar.br/submissao/index.php/2020/article/view/1813

7. Carraro FL, Pereira RF. Simuladores virtuais do PhET no ensino de física. Os Desafios Da Esc Pública Parana Na Perspect Do Profr Pde [Internet]. 2014;1. Available from:

http://www.diaadiaeducacao.pr.gov.br/portals/cadernospde/pdebusca/produco es_pde/2014/2014_uem_fis_artigo_francisco_luiz_carraro.pdf

8. Leal MM, Silva ATS, Meneses L de S. A UTILIZAÇÃO DO SIMULADOR PHET COMO FERRAMENTA DE ENSINO NAS AULAS ON-LINE DE CIÊNCIAS EM UMA ESCOLA DO MUNICÍPIO DE ÁGUA BRANCA - PI. 2020;12. 